\title{
ESTRATÉGIA INFERENCIAL PARA LER O LIVRO ILUSTRADO
}

\section{INFERENTIAL STRATEGY TO READ ILLUSTRATED BOOKS}

\author{
Márcia TAVARES ${ }^{1}$
}

\begin{abstract}
Resumo: De maneira geral a leitura de imagens no livro ilustrado ainda está relacionada à primazia da palavra e aos modos de ler em um conjunto de interdependências entre o texto escrito e as imagens. Para verificar a construção de sentidos advinda dessa relação, apresentamos a análise do livro Lá e aqui (2015), de Carolyna Moreyra, ilustrado por Odilon Moraes. Destacamos, a partir do espaço gráfico e narrativo, uma proposta de leitura permeada pelo uso das estratégias centradas em inferências, e ainda verificamos quais elementos plásticos estão dispostos no projeto gráfico e na composição do diálogo entre texto e imagem. Esses aspectos foram explorados seguindo as diretrizes de Oliveira (2008), que delimita uma primeira leitura estrutural como porta de entrada metodológica para a leitura de imagens. Para o estudo da aplicação das estratégias de inferência, tomamos Girotto e Souza (2011) e utilizamos os pressupostos inseridos na prática de leitura das palavras e na transposição de conceitos para a leitura das ilustrações do livro infantil.
\end{abstract}

Palavras-chave: Livro ilustrado. Estratégias de leitura. Inferência. Odilon Moraes.

Abstract: Generally, reading images in illustrated books is still related to the primacy of the word and to the ways of reading in a set of interdependencies between the written text and the images. To verify the construction of meanings derived from this relation, an analysis of Carolyna Moreyra's book, Lá $e$ aqui (2015), illustrated by Odilon Moraes, was carried out. From the graphic and narrative spaces, a reading proposal, which includes the use of strategies focused on inferences, was made. Plastic elements which are arranged in the graphic design and the composition of the dialogue between text and image were also checked. These aspects were considered through the guidelines of Oliveira (2008), which sets a first structural reading as the methodological starting point to read images. Girotto and Souza (2011) was the basis for the study of the application of inference; assumptions inserted in the practice of reading words and in the transposition of concepts to read children's book illustrations were also used.

Keywords: Illustrated book. Reading strategies. Inference. Odilon Moraes.

\section{Introdução}

De maneira geral, os estudos sobre a leitura de imagens no livro ilustrado elencam os modos de ler a partir de um conjunto de interdependências entre o texto escrito e as imagens, comumente verificando os graus de adequação da imagem ao texto. Esses estudos vêm aumentando, de forma considerável, ao longo dos anos e abarcando áreas das mais diversas, do design ao campo dos estudos sobre literatura e leitura. Decorrente desse pensamento, tornou-se comum reconhecer o status da ilustração como elemento inerente ao potencial de construção de sentidos no livro para crianças. Mesmo diante desse crescimento, ainda é lacunar a produção

\footnotetext{
${ }^{1}$ Doutora em Letras pela Universidade Federal da Paraíba. Professora do Programa de Pós-Graduação em Linguagem e Ensino e do Curso de Letras Língua Portuguesa na Universidade Federal de Campina Grande Paraíba. E-mail: tavares.ufcg@gmail.com
}

Revista Graphos, vol. 21, n²1, 2019 | UFPB/PPGL | ISSN 1516-1536 
de estudos sobre o conhecimento metodológico para leitura de imagens, uma vez que estamos em plena sistematização de conceitos e procedimentos.

Por outro lado, a realização gráfica do livro de literatura infantil ilustrado mostra que as relações entre as linguagens desse objeto estão mais sofisticadas, exigindo o desenvolvimento de estratégias cada vez mais específicas para a realização da leitura. Assim, há uma necessidade de maior discussão e investigação dos recursos gráficos e narrativos que constituem o livro ilustrado. O livro Lá e aqui (2015), de Carolyna Moreyra e Odilon Moraes, é um exemplo dessa intricada relação entre imagem e palavra. Em nossa análise realizaremos uma proposta de leitura para esse livro a partir do uso das estratégias de elaboração de sentido centradas em inferências. E ainda, verificaremos quais elementos plásticos estão dispostos na composição do diálogo entre texto e imagem, a partir do espaço gráfico e narrativo da obra.

Nossa investigação é de natureza descritivo-interpretativa e fundamenta-se sobre os procedimentos para realização da leitura do livro ilustrado, pautada em Nikolajeva e Scott (2011), Linden (2011), Araújo e Oliveira (2012) e Dondis (2013). Para a discussão sobre estratégias de leitura e literatura infantil Cademartori (2014), Ramos e Panozzo (2013) e Girotto e Souza (2010). Em um primeiro momento, procedemos a uma investigação analítica do livro destacado a partir de critérios como: tipo de composição (formas, cores e tipos gráficos que se destacam), linha guia de leitura visual, contorno, perspectiva, técnica, relação forma e fundo, gênero e origem de luz, esquema de tons e contrastes, tipos de figuração e linhas predominantes. Esses aspectos foram explorados seguindo as diretrizes de Oliveira (2008), que delimita uma primeira leitura estrutural como porta de entrada metodológica para a leitura de imagens. Para o estudo das estratégias de leituras que contemplem os recursos que possibilitam a construção de inferência, tomamos Girotto e Souza (2011) e utilizamos os pressupostos inseridos na prática de questionamentos que incide sobre o diálogo entre a palavra e as ilustrações do livro infantil.

O presente artigo está composto de três tópicos, dispostos da seguinte forma. Em um primeiro momento, em Breve percurso sobre a ilustração no livro infantil: modos de ler, apresentamos um trajeto sobre o espaço concedido ao diálogo entre imagem e tex to escrito no livro infantil, compilando alguns conceitos para a produção dessa leitura e percepções sobre a ilustração e suas funções. No segundo tópico, Inferência como estratégia para ler o texto e a imagem, definimos a metodologia de estudo do corpus, apresentamos as definições e estratégias de leitura de Girotto e Souza (2012), contemplando a leitura de imagens do texto com a fundamentação em Oliveira (2008) sobre recursos de elaboração de sentidos a partir dos elementos gráficos. Por fim, apresentamos e descrevemos, em Lá e aqui: diálogos entre texto 
e imagem no livro infantil, a obra em destaque, o livro Lá e aqui (2015) de Carolyna Moreyra e Odilon Moraes. Objetivamos, nessa investigação, refletir sobre as potencialidades da leitura que relaciona as linguagens presentes no livro ilustrado e, ainda, explicitar modos de ler por meio de questionamentos centrados na elaboração de inferências.

\section{Breve percurso sobre a ilustração no livro infantil: modos de ler}

Atualmente, o livro infantil é constituído por elementos de texto e de imagem, resultado do acúmulo de transformações que essas linguagens sofreram na feitura desse objeto ao longo do estabelecimento de sua configuração como um artefato cultural. Nesse percurso, faz-se necessário considerar as alterações ocorridas com o estatuto da literatura para criança e a própria condição do livro como objeto físico. Esses dois pontos cruciais ocupam hoje lugar importante nas discussões sobre o ensino de leitura e a formação do leitor, sobre os recursos de análise estética e sobre a constituição de acervos de literatura infantil.

Nesse percurso, destacamos alguns autores que já discutiam a necessidade de pensarmos sobre os modos de ler o livro ilustrado e sobre os elementos que se constituem como determinantes para delimitar os aspectos materiais de composição de sentido. Uma das primeiras autoras a discutir essas questões, Regina Yolanda Werneck em "O problema da ilustração no livro infantil” (WERNECK, 1983), registra o aumento do interesse do conjunto de formadores de leitores, editores e especialistas sobre o livro ilustrado. A autora defende a necessidade do espaço para a ilustração no livro para o leitor que ainda não lê o código escrito, e mais, destaca que a ilustração seria "a pausa e o devaneio" para o desenvolvimento da leitura criadora. Esse conceito de leitura amplia a noção de formação do leitor por fases, e justifica a ideia de processo. Segundo Werneck "a leitura criadora é o resultado da percepção única e individual, graças às combinações perceptivas que se realizam e que fazem com que nunca uma pessoa descreva o que leu exatamente como o outro" (WERNECK, 1983, p. 119). Dessa forma, a ilustração também é literatura, pois evoca a linguagem verbal, oral e escrita, provoca a concatenação de várias linguagens, induz o leitor a formar conexões entre os índices que encontra nas imagens, e, assim, contribui decididamente para a formação do leitor.

Ainda no início desse processo, Luís Camargo, escritor e ilustrador, em seu livro Ilustração do livro infantil (1995), destaca que o crescimento dos estudos sobre a ilustração é mais frequente depois da década de 1970, e credita boa parte dessa iniciativa aos estímulos da Fundação Nacional do Livro Infantil e Juvenil e ao Centro de Estudos de Literatura Infantil e Juvenil. O próprio autor é um dos responsáveis por textos, artigos e publicações sobre esse 
tema. Camargo discute desde a nomenclatura, os estilos e as técnicas até as peculiaridades de projetos gráficos que particularizam o livro de imagem e o livro de poesia. Destacamos o capítulo sobre a história do livro infantil ilustrado, que apresenta quatro obras publicadas entre 1920 e 1969, que são exemplares de algumas das mudanças ocorridas nas formas e técnicas para a ilustração nesse período. Vejamos, no quadro abaixo (Quadro 1), algumas das considerações de Camargo para obras que, posteriormente, se tornariam referência das modificações ocorridas nesse período:

Quadro 1 - Obras analisadas por Camargo (1995)

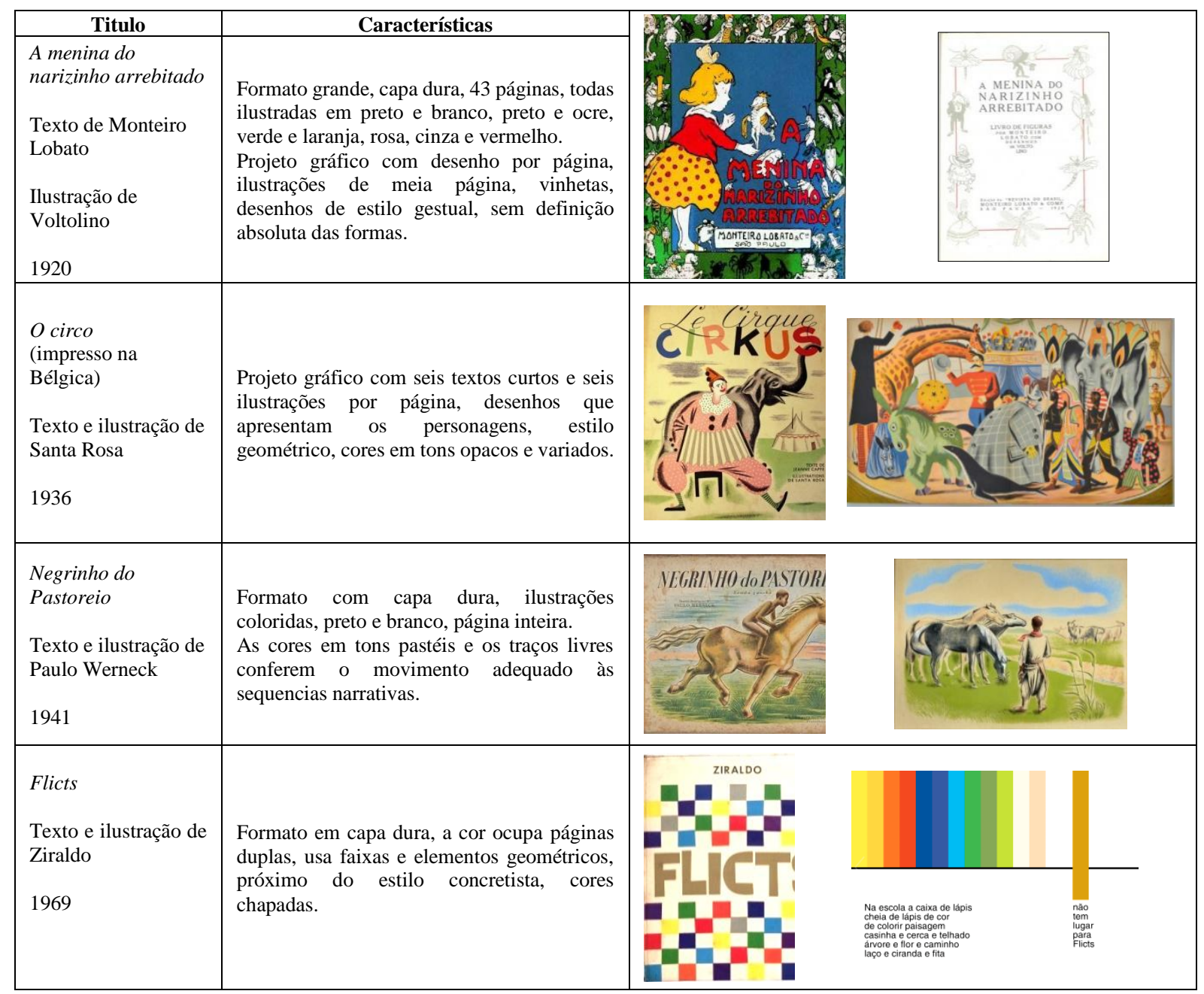

Fonte: Montagem a partir de imagens em https://colecaolivrodeartista.wordpress.com e de Camargo, 1995.

No conjunto em destaque no Quadro 1, as informações sobre os livros e sua composição apresentam a diversidade de técnicas e o uso de recursos variados, desde o tamanho das obras até a disposição da imagem impressa, que atestam a renovação gráfica e visual dos livros ilustrados. Essa diversidade é o cerne das funções que o autor atribui à ilustração, apoiado nas funções da linguagem de Roman Jakobson: representativa, descritiva, narrativa, simbólica, expressiva, estética, lúdica, conativa, metalinguística, fática e de pontuação. $\mathrm{O}$ aspecto que 
parece mais significativo, é a perspectiva sobre um modo de ler que parta da forma como o texto e a imagem dialogam, sem que haja o predomínio de um sobre o outro.

Essa perspectiva de diálogo é corroborada por Maria Alice Faria: “em princípio, a relação entre a imagem e o texto, no livro infantil, pode ser de repetição e/ou de complementaridade, segundo os objetivos do livro e a própria concepção do artista sobre a ilustração do livro infantil" (2004, p. 34). A autora propõe modos de leitura centrados na classificação de Poslaniec e Houyel em três níveis: 1) a leitura comprometida, que se concretiza na identificação do leitor com o livro, enredos e personagens, sem confrontos com sua realidade imediata, 2) a leitura aprofundada pela experiência pessoal que capacita discernir no texto conotações ideológicas e contextos históricos, e 3) a leitura literária centrada nas capacidades de perceber as construções estéticas e sentidos implícitos no texto. Ponto alto da proposta é a delimitação de elementos de hipersignificação da narrativa como elementos estáticos, construtores da descrição e sugestão, e os elementos dinâmicos como relacionados ao encadeamento lógico das ações narrativas.

Outro título que busca uma metodologia para leitura centrada no diálogo é Olhar de descoberta (2003), de Lúcia Pimentel Góes, que tem por subtítulo “proposta analítica de livros que concentram várias linguagens". Neste, há uma concepção de leitura como fenômeno complexo que necessita da atuação do leitor como coautor, pois é ele que coproduz e atribui sentidos ao que está lendo. Para a autora, o livro de literatura infantil é um objeto de leitura plural que utiliza recursos de linguagens diversas, artes e técnicas de cinema e televisão, quadrinhos e elementos de design gráfico para produzir sentidos. Dessa forma, a autora destaca as várias possibilidades de criação, apresentando soluções de leitura variadas para as narrativas, desde o livro brinquedo até a constituição intertextual do livro de imagem e alguns esboços de planos para aplicação de estratégias de leitura.

A formação do leitor de imagens é o centro da discussão empreendida por Graça Ramos em A imagem nos livros infantis: caminhos para ler o texto visual (2013). A autora defende que a existência de maior espaço dedicado ao visual no livro infantil promove uma problemática, pois exige mais atenção advinda do leitor, precisamente por provocar novas associações e fomentar o imaginário visual. Uma vez que "o conjunto de imagens (...) requer um pensamento visual capaz de absorver da maneira mais ampla possível mensagens que [o] livro infantil pode conter" (RAMOS, 2013, p. 30), é necessário estabelecer formas de acesso ao aprendizado da leitura de imagens, ou seja, um alfabetismo visual, modos de educar o olhar para a percepção de elementos composicionais do projeto gráfico, cores, formas, modos de 
contemplar o todo do livro, matizes, ritmos de cores, contrastes entre planos, composição de personagens. Essa perspectiva é análoga ao que defende Donis A. Dondis, para o qual o alfabetismo visual deve ocupar as mesmas prerrogativas e determinações de função para constituição do sujeito leitor que a formação de alfabetismo dada ao aprendizado das palavras. Segundo o autor, o alfabetismo visual é o domínio de "um sistema básico para a aprendizagem, a identificação, a criação e a compreensão de mensagens visuais que sejam acessíveis a todas as pessoas" (DONDIS, 2007, p. 3).

Ramos parte do pressuposto de que esse alfabetismo pode e deve começar nas leituras do livro infantil, seja ilustrado, de imagens ou mesmo o $e$-book, uma vez que todos carregam as estratégias de formação de significados que precisam ser apreendidos pelo leitor para que se concretize a leitura literária. A indistinção de público seria uma característica da produção contemporânea, que exigiria esse aprendizado. O capítulo final de Graça Ramos é dedicado a anotações para a leitura visual, em se tratando do intento principal do livro, que é ser um guia bastante produtivo para a conceituação do alfabetismo visual. A concepção de leitura de Ramos para a produção do alfabetismo visual inclui a utilização de alguns termos mais comuns ao campo do design gráfico e da comunicação visual para a produção de metodologias de interpretação das imagens. O seu guia de leitura é imprescindível, pois encaminha o leitor para pontos necessários da mediação e pode suscitar novas leituras, apoiadas por dados recolhidos do texto verbal e da ilustração que compõem a narrativa visual.

Marisa Lajolo e Regina Zilberman, na obra Literatura infantil brasileira - histórias e histórias, afirmam que, na década de 1980, a linguagem visual migrava para o centro das obras, "e não mais como ilustração e/ou reforço de significados confiados à linguagem verbal" (1991, p. 128). A lista de títulos apresentada pelas autoras também confirma esse momento de ampliação do espaço dado à imagem no livro infantil em obras como Flicts (1969), de Ziraldo, Domingo de manhã (1976) e Ida e volta (1976), ambas de autoria de Juarez Machado. A afirmação sobre essa centralidade da ilustração atesta um dado da época, fundamental para registrar a modificação e marcar o início dessa discussão. Em obra recente, de 2017, as duas autoras retomam a discussão sobre novos espaços de criação do livro para criança e atestam a consolidação desses espaços e o incremento das novas possibilidades de expressão incorporadas pelos meios de comunicação. Nesse quadro atualizado, a informação não é mais construída a partir da lógica linear da palavra disposta no papel, mas, sim, a partir de uma organização regida pelo vaivém habitual dos objetos digitais e sua lógica iconicial. Para Lajolo e Zilberman (2017), por conta desse processo de apropriação os autores são "estimulados a importar técnicas e 
processos inusuais no mundo do livro impresso, porque provêm de outros suportes." (LAJOLO e ZILBERMAN, 2017, p. 102).

Ao cotejar esse breve panorama sobre alguns modos de ler a ilustração no livro destinado ao público infantil, percebe-se uma mudança na perspectiva: antes a imagem ocupando uma função explicativa e auxiliar junto ao texto escrito, este como prioridade; e posteriormente, uma ampliação dessa função para o entendimento da imagem estabelecendo outros sentidos, na medida em que os recursos para produção do livro foram se sofisticando. Camargo (1995), Faria (2004) e Ramos (2013) são exemplos de uma perspectiva de leitura que busca modos de ler o livro ilustrado definido por categorias e procedimentos de leitura específicos. É nessa perspectiva que desenvolvemos a discussão sobre a necessidade de ampliar as possiblidades de leitura dos livros ilustrados considerando sua materialidade. Na seção seguinte apresentaremos as estratégias de leitura a partir da exposição de Girotto e Souza (2010), e os meios de construção de sentidos resultantes do diálogo entre as linguagens presentes no livro ilustrado de literatura infantil.

\section{Sobre estratégias de leitura para o texto e a imagem}

As definições sobre estratégias de leitura para o texto possuem arcabouço teórico nas observações de Girotto e Souza (2010), que determinam a literatura infantil como uma fonte de manifestação cultural, sobre a qual o leitor cria, recria e da qual se apropria com elementos de imaginação e com recursos do conhecimento prévio adquirido. Segundo as autoras, a possibilidade de construção de sentidos em uma obra já se estabelece nos elementos paratextuais, que são responsáveis por informações necessárias antes de a criança começar a leitura do texto escrito. No processamento da leitura as autoras consideram os movimentos de metacognição, ou seja, o processo de pensar e compreender o texto. Um trabalho com as estratégias de leitura possibilita o entendimento do que foi lido, levando a perceber como ocorre a formulação de imagens, como as ideias são sintetizadas ou como as inferências podem ser produzidas para organizar a compreensão do texto. As autoras (2010) organizam suas observações delimitando as estratégias de: conexão, inferência, visualização, questionamento, síntese e sumarização.

É a partir das considerações sobre os processos que ocorrem antes, durante e depois da leitura que Girotto e Souza (2010) discutem como as estratégias podem ajudar na formação de leitores proficientes. Para as autoras o uso sistematizado e a condução mediada levam ao Letramento Ativo, no qual o leitor toma consciência do uso que faz do instrumento de leitura, 
o que só é possível com o entendimento do mecanismo de cada uma dessas estratégias. Esse leitor que pratica o letramento ativo se utiliza da associação das ideias, do conhecimento prévio para reconhecer a ideia principal da narrativa, atribuir sentido ao que é fundamental e construir e rever as informações levantadas na fase da pré-leitura. Não há impedimento, segundo as autoras, de essa sistematização ser implementada desde a educação infantil. O que nos faz adotar a mesma consideração para o entendimento da leitura de imagens, uma vez que as atividades e práticas de leitura com crianças não alfabetizadas podem ser centradas no livro de imagem ou no livro ilustrado.

As estratégias de leitura são "procedimentos de caráter elevado, que envolvem a presença de objetivos a serem realizados, o planejamento das ações que se desencadeiam para atingi-los, assim como sua avaliação e possível mudança" (SOLÉ, 1998, p. 70). No entanto, não devem ser entendidas como um fim em si mesmas; na verdade, trata-se de meios de produção de compreensão leitora. A afirmação de Solé se amplia para o entendimento das estratégias como procedimentos e, como tal, são passíveis de serem ensinadas. Além disso, é necessária a compreensão de que "deve predominar a construção e o uso de procedimentos de tipo geral, que possam ser transferidos sem maiores dificuldades para situações de leitura múltiplas e variadas" (SOLÉ, 1998, p. 70). Dessa forma, é possível estender o uso das estratégias para as múltiplas e diversas leituras possíveis a partir das linguagens presentes no livro ilustrado. Como objeto multifacetado e carregado de significados culturais, o livro ilustrado possibilita a formação de um leitor de maneira global, pois exige que esse leitor faça uso de suas habilidades e desenvolva competências para o aprendizado da leitura. Dessa forma, estipula-se que os leitores são estratégicos quando buscam conexões entre o conhecimento que já detêm e o conhecimento novo; fazem perguntas ao texto; estabelecem inferências a todo o momento; visualizam e constroem imagens; distinguem ideias importantes e produzem sínteses e, por fim, fazem o monitoramento adequado do entendimento produzido ao longo da leitura. (GIROTTO e SOUZA, 2010).

Inferir é um processo que requer do leitor uma conclusão ou interpretação do que não está explícito no texto, uma vez que entendemos que é necessário construir a informação final a partir do entrecruzamento de duas ou mais informações que estão no texto ou de pistas colocadas no texto visual. Segundo Girotto e Souza (2010), o processo de construção de inferências pode ocorrer em conjunto com o acionamento do conhecimento prévio no começo da leitura e também durante a leitura, sustentando-se em características encontradas no texto para elaboração de previsões apuradas e significativas. Para as autoras o conhecimento prévio 
é uma estratégia essencial, pois ativa o repertório que os leitores já possuem e que vão utilizar para entender o texto. E junto ao conhecimento prévio, os leitores inferem ao utilizar as informações que já sabem, a partir dos seus conhecimentos prévios, e ao tentar predizer do que trata o texto construindo sentidos para ele. Nesse sentido, a estratégia inferencial é concretizada através de dicas encontradas durante a leitura, e possibilita ao leitor fazer o movimento de ida e vinda entre os elementos visuais e de texto escrito do livro ilustrado.

Assim, a produção da leitura no livro ilustrado realiza-se a partir da conjunção entre o elemento plástico e o narrativo, e é esse funcionamento que garante o entendimento do enredo. A adequada ampliação dos significados se concretiza na relação de equilíbrio entre as linguagens que organizam as informações nesse tipo de livro infantil. Sobre essa sistematização de informações, Solé enfatiza que "a organização interna de um texto oferece algumas pistas que permitem um conjunto de questões cuja resposta ajuda a construir o significado do texto" (SOLÉ, 1998, p. 111). É a partir do reconhecimento dessa disposição interna de informações contidas no livro ilustrado que podemos direcionar as perguntas ao texto escrito e, da mesma forma, formular indagações sobre as ilustrações presentes na composição das obras. Assim, o potencial para estabelecer inferências encontra-se também na leitura das imagens que fazem parte do livro ilustrado. O alto nível de elaboração gráfica que caracteriza as obras infantis contemporâneas torna primordial esse procedimento de busca por pistas na organização interna do livro. Nesse movimento de construção de significados, atentar para os detalhes contidos nas imagens dispostas nas páginas atesta o caminho para a formação do leitor estratégico. Tomando por base essa delimitação, o livro Lá e aqui, de Carolina Moreyra e Odilon Moraes, de 2015, é bastante exemplar para uma leitura permeada pela estratégia inferencial. Passamos a seguir a analisá-lo.

\section{Lá e aqui: diálogos entre texto e imagem no livro infantil}

O livro Lá e aqui (2015), de Moreyra e Moraes, se apresenta em 56 páginas, de dimensões enxutas, $16 \times 16 \mathrm{~cm}$, capa dura, brochura, guardas em azul, paleta de cores em tons claros e pastéis, com nuances de volume sugeridas pela variação de tonalidades. Não há nota técnica sobre a gramatura do papel, nem sobre o tipo, mas a fonte sem serifa garante o recorte simples que se coaduna com as ilustrações em lápis de cor. A linha estética é minimalista (o mínimo de elementos, cores e traços) e segue essa proposta centrada em índices e na sugestão do tema e sentimentos. Nada é dito de forma óbvia: há sempre uma delicadeza em expor os acontecimentos, os espaços, as pessoas e os bichos. 
Entre imagens de páginas duplas, sem margens e sem fundo, a história se estabelece através de jogos metonímicos de apresentação dos elementos gráficos que compõem o ritmo narrativo. Podemos dizer que o espaço da página e o narrativo são usados de forma estratégica, e o jogo de significados entre casa e moradores, lá e aqui, segmenta a narrativa entre os momentos do antes e do depois. Os recursos gráficos vão construindo um ritmo visual que origina a apresentação dos personagens e da ação, além de determinar o lugar e o espaço de cada um. O protagonista é uma criança que vivencia o processo de separação dos pais e vai expondo como acontece o afastamento à medida de sua perspectiva de filho. É a criança, sem nome, assim como todos os personagens da história, que dita essa perspectiva e guia o leitor aos acontecimentos da narrativa. O primeiro chamamento é o clássico "Era uma vez....”. A partir daí se estabelece uma sucessão de elementos que indiciam os acontecimentos e espaços. É significativo estabelecer essa relação, uma vez que cada elemento visual se relaciona ao que vai acontecer posteriormente. O leitor será guiado pela voz narrativa infantil e vai esperar, claro, seguindo a trilha de inferências e pistas visuais, o desfecho das ações a partir do que constrói como significado de sua leitura. Nem sempre essa pista seguirá para uma resposta óbvia e, assim como o texto, é preciso seguir perguntando aos elementos dispostos se é possível construir aquele sentido ou não, pois, em boa parte do livro, o que se havia pensado se desfaz ao virar da página.

No livro como um todo há elementos plásticos que nos ajudam a seguir a combinação dessas linguagens; no caso da imagem temos: o tipo de composição, as formas geométricas e a linha guia de leitura visual, tipos de contorno, perspectiva, técnica utilizada, relação forma e fundo, gênero e origem de luz, esquema tonal, contraste de cores, figuração, gênero da imagem, linhas predominantes, tipos de sombra, sentimento despertado pela ilustração no leitor. Desses elementos, respeitando a proposta do projeto gráfico para a obra de Moreyra e Moraes, destacamos de forma diluída nos comentários: perspectiva, gênero e origem de luz, tipos de sombra, linha guia de leitura, e sentimento despertado pelas imagens como resultado da leitura empreendida.

A intenção é fazer uma leitura que possa utilizar as estratégias de construção de sentido concentradas nas inferências e destacar da composição gráfica quais elementos podem ser pinçados para cada momento do livro. Além disso, indicaremos quais elementos plásticos estão dispostos no projeto gráfico e na composição do diálogo entre texto e imagem, considerando que temos uma exposição de poucos detalhes, sem margem e com paginação dupla. Inicialmente, a partir das informações da capa (Figura 1), seguimos as sugestões de Girotto e 
Souza (2012), como: a) inferir o significado de palavras; b) inferir pela capa e ilustrações, assim como pelo texto e c) inferir os temas da narrativa.

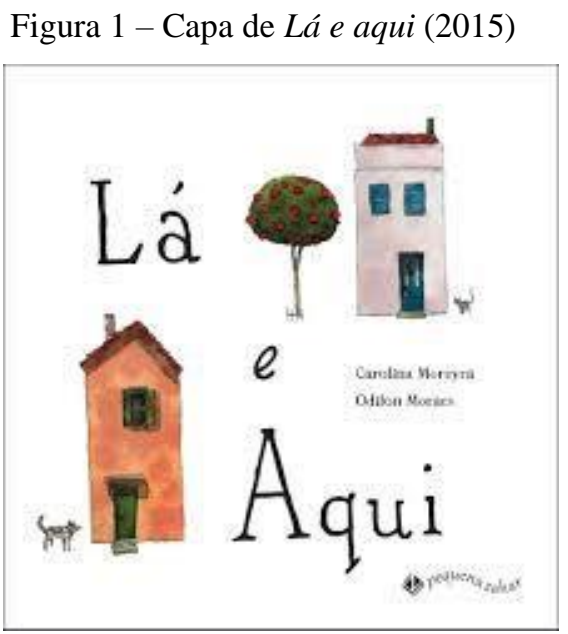

Fonte: Moreyra e Moraes (2015)

A partir da capa do livro, destacamos as possibilidades de inferência. Necessariamente, as palavras já estabelecem um distanciamento espacial, e a imagem dá base para essa informação. A construção da diferença pode ser levantada entre as imagens das duas casas que compõem a capa, em que várias diferenças são marcantes. É importante sinalizar essas diferenças chamando a atenção do leitor para formas do telhado, cores das fachadas, bichos que circulam ao redor, árvore em apenas uma casa, entre outros. É significativo atentar que podemos inferir desde a capa que teremos dois lugares para as ações; no entanto, após o início da história essa expectativa não é imediatamente confirmada. Posteriormente, se atentarmos para os índices nas páginas subsequentes, podemos pensar nessa hipótese. É preciso considerar que o afastamento pode ser algo a inferir, mas não a motivação do título. Para o levantamento dessas inferências, o momento de análise da capa deve priorizar os dados percebidos pelos leitores e suscitar discussão a partir de questionamentos como: O que vemos na capa? Sobre o que trata essa história? É possível saber onde é o LÁ e o AQUI?. À medida que o texto e a imagem avançam, é mais difícil definir quais pontos são determinantes para estabelecer a distância. LÁ como longe e AQUI como mais próximo. O leitor relaciona as possibilidades à medida que o texto avança, ou seja, com a leitura do texto verbal, procede à verificação das inferências à medida que procede à leitura.

Ao folhear as primeiras páginas, o leitor vai se deparar com o acréscimo paulatino de cada elemento citado no texto e apresentado junto da imagem, sempre seguindo a ordem de apresentação dos menores detalhes para os maiores. Os recursos gráficos vão construindo o ritmo visual que sugere o movimento de apresentação entre lá e aqui, dos personagens. A cada Revista Graphos, vol. 21, n² 1, 2019 | UFPB/PPGL | ISSN 1516-1536 
página, as cores e os traços usados retomam o mesmo pano de fundo branco em momentos diversos da ilustração do livro como um todo. O fundo branco das páginas e a abertura sem margem sugerem uma narrativa simples e concisa, e os artigos indefinidos também reforçam o que as imagens nos trazem. É uma história comum com pessoas comuns, não há aventuras ou reviravoltas.

O livro apresenta em todas suas páginas uma perspectiva estática; não há modulação da visão do leitor, sempre de frente aos acontecimentos, de fora para dentro da casa e da esquerda para a direita. Com relação ao uso da luz e tipos de sombra, há uma variação que condiz com o andamento da narrativa. $\mathrm{O}$ uso da mesma perspectiva confere estaticidade ao momento de apresentação gradativa dos personagens e dos elementos, que é garantida pela interferência do narrador/ilustrador que usa o espaço das folhas para dar continuidade ao movimento. Carolina Moreyra e Odilon Moraes recorrem aos traços simples, ao centramento em pequenos detalhes, a uma só dimensão dos objetos e corpos, entre outros recursos que sugerem uma ideia de continuidade entre o traço e a proposta de apropriação dos sentimentos de separação e mudança vividos pelo personagem criança. Na Figura 1, da capa, o olhar é conduzido para os cantos e lados, para o alto e para baixo da página e reforça a proposta de distanciamento dos espaços, além de criar a possibilidade de permuta pela alocação das palavras lá e aqui, aqui e lá.

O texto, por sua vez, também se insere de modo sutil nas páginas, e coaduna-se com a perspectiva de mínimos estímulos para a ampliação de sentidos e significados. E em um momento especial não há texto. Assim, quando a apresentação do que há na casa encerra com a citação de 'Um pai e uma mãe', segue-se esta página sem texto (Figura 2), apenas com a imagem da chuva que cai. Vejamos:

Figura 2 - Início da chuva

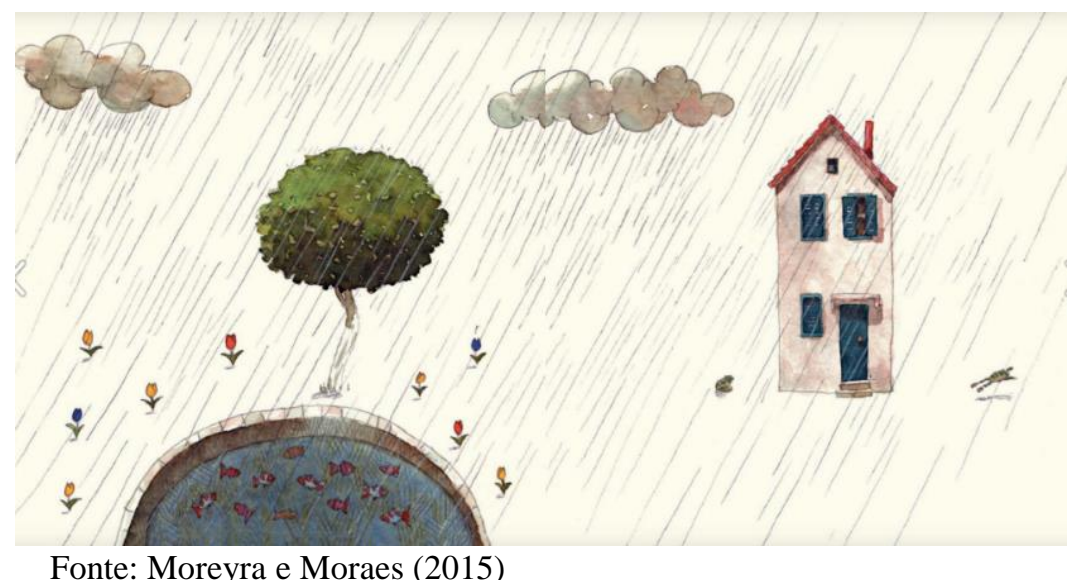

Fonte: Moreyra e Moraes (2015)

A chuva é acrescida ao espaço da narrativa na folha, mas sem anunciação, chega sem aviso e se estabelece por cinco páginas. Rompe a sequência harmônica e verticalizada, inunda Revista Graphos, vol. 21, n²1, 2019 | UFPB/PPGL | ISSN 1516-1536 
a história e chega até o topo da página, embora a paleta de cores e os tons esmaecidos já preparassem o olhar do leitor para uma chegada sutil das cores em tons mais frios. Temos, assim, os tons de verde, sempre em fundo branco, rosa, azuis em muitas variações, uma presença discreta de vermelho terra e alaranjados, além da ascensão dos tons de roxo e azul escuro forte. Obviamente, a cor carrega uma forte carga narrativa e conduz o olhar para o clímax do enredo quando de fato ocorre a separação dos pais. A metáfora da inundação é construída tanto no texto quanto na imagem, sempre pautados pelas palavras do narrador/criança, mas sem explicitação dos seus sentimentos no texto. Temos o destaque no texto que inicia com o afogamento da casa, e em seguida, a saída dos personagens e a modificação do espaço; os cachorros fugiram, as flores murcharam, o jardim morreu, e por fim, a constatação: a casa ficou vazia.

Figura 3 - Sequência de imagens da água da chuva
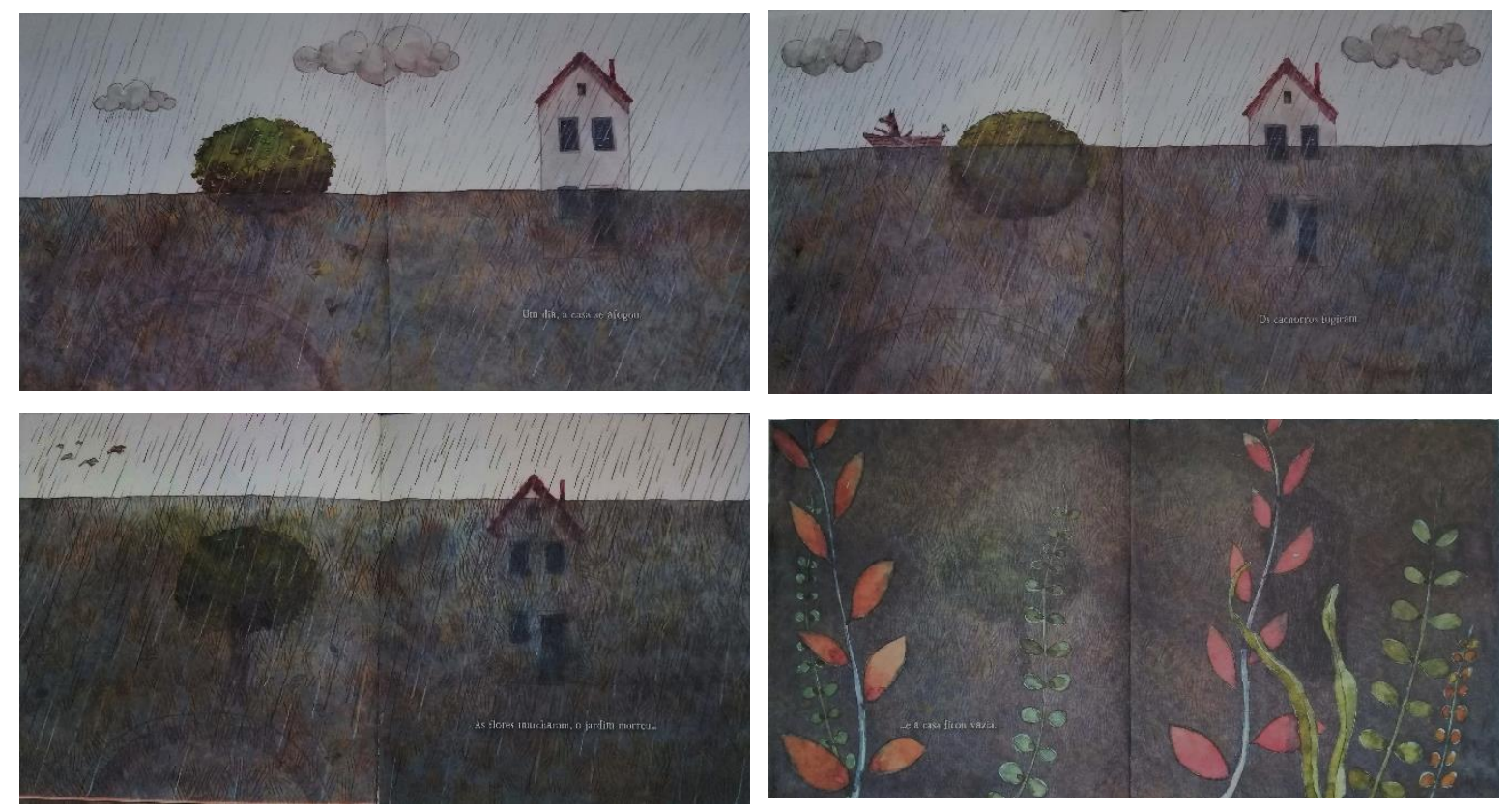

Fonte: Moreyra e Moraes, (2015)

A distribuição da luz traça a mudança dos espaços. Na Figura 3, a imagem e o texto trazem a clivagem, representada na chuva que encharca, afoga a casa e divide a folha em duas: há uma linha horizontal que, mais uma vez, possibilita a inferência de que algo vai acontecer para dividir os espaços, já que a casa está cortada pela água e a página dupla cortada pelos tons diferentes. O texto é composto agora de ações; se antes as personagens eram apresentadas uma a uma, agora cada uma toma uma direção diferente. A casa se afogou, os cachorros fugiram, as flores murcharam, o jardim morreu e a casa ficou vazia. A ampliação do espaço inundado é apresentada ao leitor pela mudança de perspectiva. Começamos a ver a casa de longe e de dentro 
da chuva; páginas escuras substituem o fundo branco dominante nas páginas anteriores. No entanto, é necessário chamar a atenção do leitor para o ritmo do afogamento, pois é aos poucos que o processo de elevação da água acontece. Cabe perguntar, para compor essas leituras: Como ocorre o afogamento da casa? Como os cachorros fogem? Como as plantas aparecem depois do afogamento da casa? O que ocorre com os passarinhos que não são citados no texto? Cabe levantar no texto e na imagem todos os personagens que moravam na casa e no seu arredor, no jardim, no lago, na árvore. Esse levantamento poderá colaborar para a construção dos questionamentos de ordem inferencial.

$\mathrm{Na}$ imagem da Figura 4 prevalece o uso dos tons mais escuros e a sensação é de aproximação dramática dos olhos da mãe: a sequência de páginas de fundo branco, já quebrada antes, agora é rompida com um zoom no rosto da personagem, com a composição fechada, crua e o predomínio de menos luz que a panorâmica e, por fim, a pequena luz dentro dos olhos em meio aos peixinhos vermelhos. O texto condensa a angústia da mãe e a perspectiva infantil, que transforma a dor da separação em imagem: "Os peixinhos foram morar nos olhos úmidos de minha mãe”, e no caso do pai: "Os sapos levaram os ensopados pés de papai para longe."

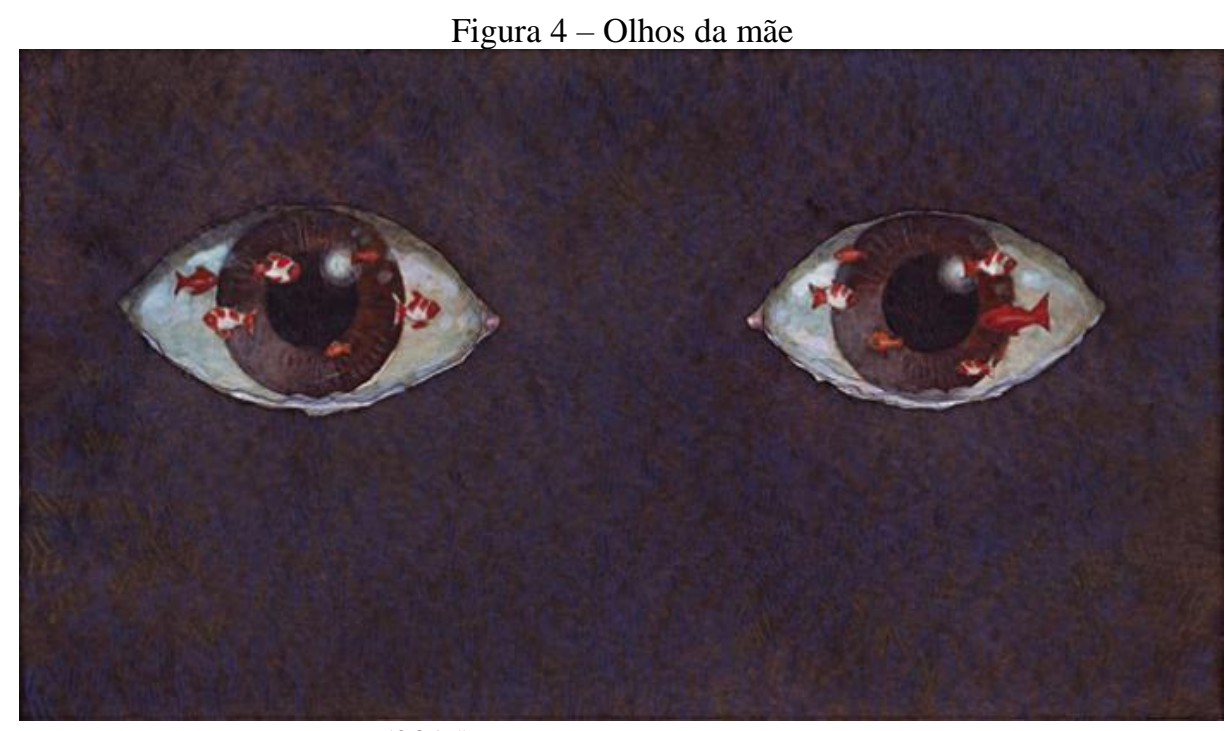

Fonte: Moreyra e Moraes (2015) 
Figura 5 - Pernas do pai

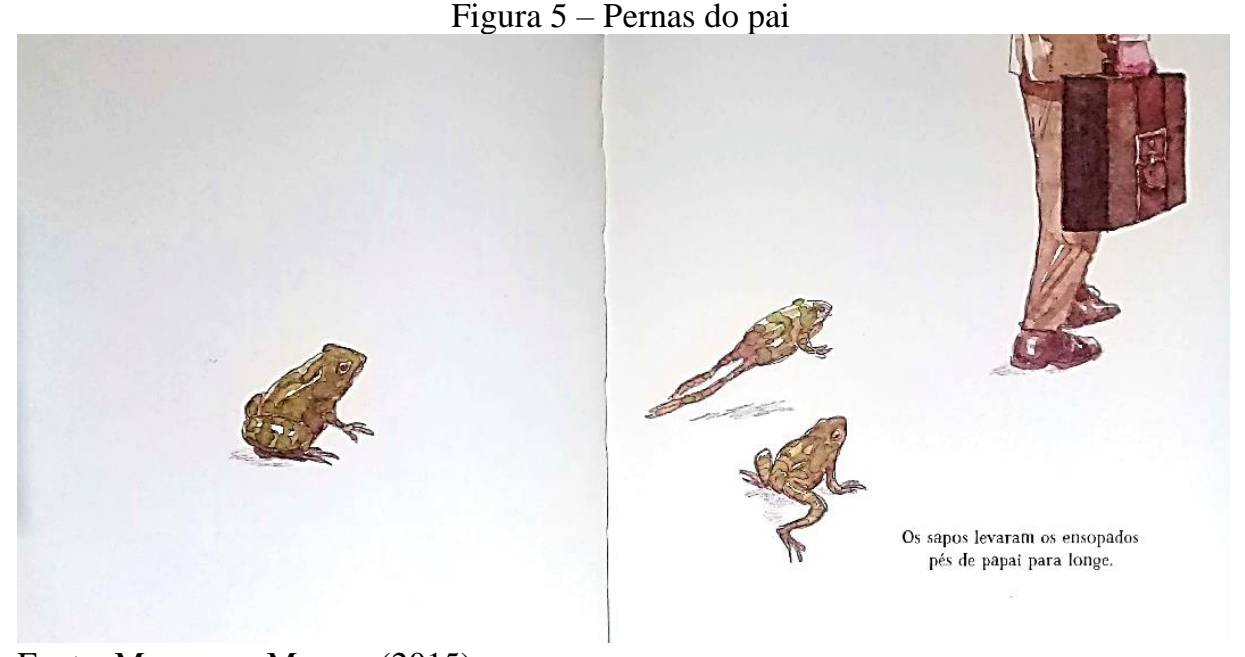

Fonte: Moreyra e Moraes (2015)

Para continuar no movimento de construção de sentido, podemos ler as Figuras 4 e 5 em contraste comparativo. Temos muitos indícios para compor a leitura: Como os bichos aparecem nas imagens? Qual a posição de cada personagem? O que os olhos e as pernas revelam? Nesse momento de divisão, é necessário instigar no leitor perguntas sobre as imagens e as atitudes de tristeza da mãe e de saída do pai. O texto enuncia de forma poética essas atitudes e as associa à fuga dos animais, uma vez que os peixinhos e os sapos também ficaram sem casa e buscam outros lugares para morar. Lembrando que essa é a visão do filho. A separação se concretiza.

É significativa a perspectiva cultural de que o pai saiu de casa, não sem consequências para ele, claro... os pés ensopados trazem o caráter de peso e medida para sua parcela de sentimento. A imagem do pai "saindo da página" também é indício desse movimento, e é seguida pela resolução da separação: "Nossa casa virou duas" (Figura 6), texto disposto na página esquerda e sem acompanhamento de imagem, sem correspondência texto e imagem, como estabelecido na feitura do livro até esse momento da narrativa. 
Figura 6 - Divisão das casas

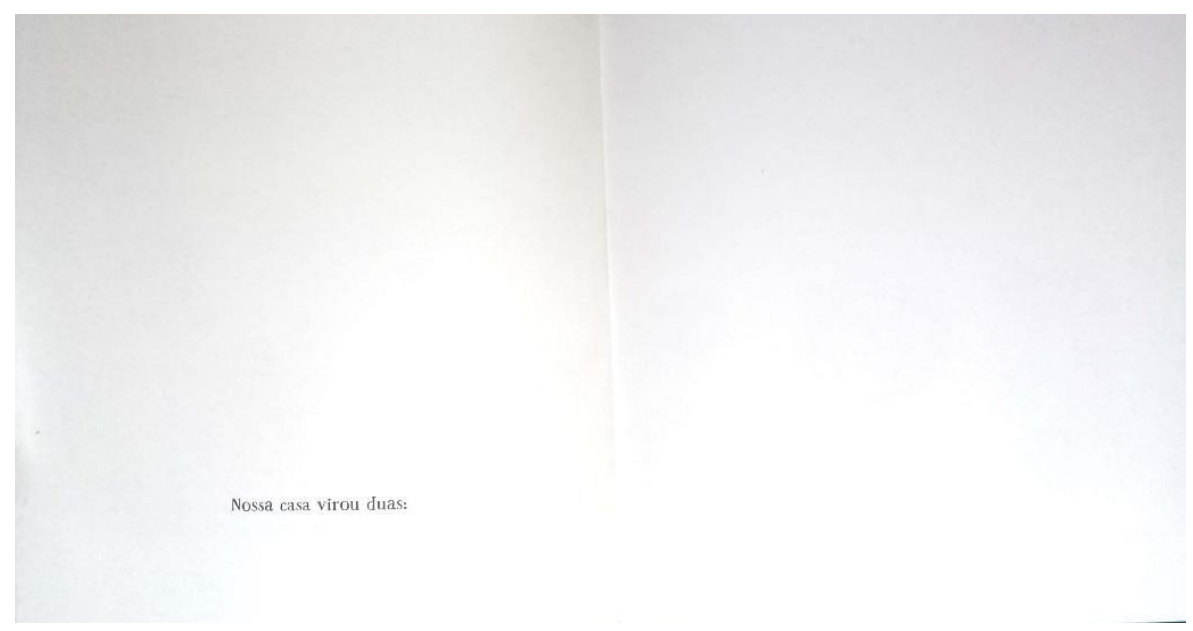

Fonte: Moreyra e Moraes (2015)

Para pensar sobre os possíveis sentidos dessa página sem imagens, é necessário indagar: Por que não há imagem? Qual a relação entre o emprego do pronome possessivo e o espaço em branco? O que podemos concluir diante da ausência da imagem? Como o que era uma casa, nossa casa, poderia agora virar duas? Seguindo o ritmo da narrativa, percebemos esse espaço vazio/branco como a pausa depois do afogamento da casa/separação dos pais. O branco simboliza a passagem, o recomeço, em várias culturas. O leitor precisa retomar as ações anteriores para construir o sentido do espaço do recomeço, pois não há tradução para o hiato de tempo que foi necessário para essa reconstrução de relações, sentimentos e espaços.

As imagens que se seguem trazem enfim as duas casas: uma da mãe e outra do pai. Aqui cabe fazem um exercício de comparação entre as duas habitações: Qual apresenta mais detalhes? O que eles podem sugerir? Como as casas estão dispostas na página? Como se particularizam? Repetem traços e cores? Na apresentação dos espaços internos, quais ambientes são destacados? Por quêe? Agora o pai e a mãe, moradores que foram apresentados por último na primeira parte do enredo, estão cada um em seu lugar. Os detalhes internos da casa são postos, mais uma vez, sem fundo, em primeiro plano. Para a casa da mãe o destaque é a poltrona e a televisão, e, segundo o filho, tem cosquinha. No espaço do pai, o ambiente é o do quarto, com violão e bola de futebol, acompanhado do texto: tem história e violão. Deve se direcionar o entendimento de que o espaço interno foi apresentado aqui pela primeira vez, o que traz a sensação de proximidade para o olhar do leitor. A observação dos detalhes é fundamental para estabelecer essa relação entre o antes e o agora, e, fazendo referência ao título, aos espaços, entre o lá e o aqui. 
O texto é acompanhado pelas imagens e agora as informações são substituídas por uma cena direta dos espaços, significativamente elaborados nas páginas com fundo branco e sem paredes, ou seja, os elementos gráficos se dispõem para a criação de uma leitura coerente com a trama e em perfeita harmonia com o sentido da narrativa, estabelecendo um ritmo sensível às mudanças de cenário e coerente com a diagramação do livro. Para Van der Linden (2011) "a diagramação é trabalhada no intuito de articular formalmente o texto com as imagens" (p. 47). Dessa maneira, é a disposição do texto, ora na página esquerda, ora na página direita, sempre centralizado na margem inferior do livro e sempre sucinto, que conduz o olhar do leitor no trajeto da imagem para a palavra, da palavra para a imagem, e assim garante "um ritmo de leitura equilibrado entre as duas expressões" (LINDEN, 2011, p. 47)

Na sequência do enredo, os outros moradores voltam para os seus lugares: os peixinhos para o aquário, os sapos para o jardim. Essas informações estão no texto e na imagem. No entanto, a informação de que os cachorros ficaram com o pai e que a mãe tem um gato estão apenas a na imagem. Esse dado funciona para o leitor estar atento aos indícios que podem construir cada informação, a presença de um dado apenas na imagem demanda ao leitor estabelecer uma coerência entre a informação visual e o que se encontra em outras partes do texto na obra ilustrada como um todo. É bem comum que a informação de algum dado novo ou de explicação esteja na imagem.

Após a resolução do enredo, o pequeno narrador apresenta sua nova casa. A narrativa se aproxima do seu final. Para a leitura efetiva da imagem que fecha a obra (Figura 7), é necessário refletir e realizar o movimento de ida e vinda entre texto e imagem. O processamento dos sentidos da separação expostos nas páginas demanda o conhecimento de que a criança fica em momentos diferentes com cada responsável, quando os pais se separam. Via de regra, esse tempo deve ser dividido de maneira igualitária. É relevante, dessa forma, indagar: E nas últimas imagens o que pode sugerir a distribuição das casas separadas em pontos diferentes das páginas duplas? O que se revela na retomada do título: lá e aqui? Como o pai e a mãe recebem o menino? Quais as ações que cada um realiza já dentro da casa? 
Figura 7 - Divisão entre a casa do pai e a casa da mãe
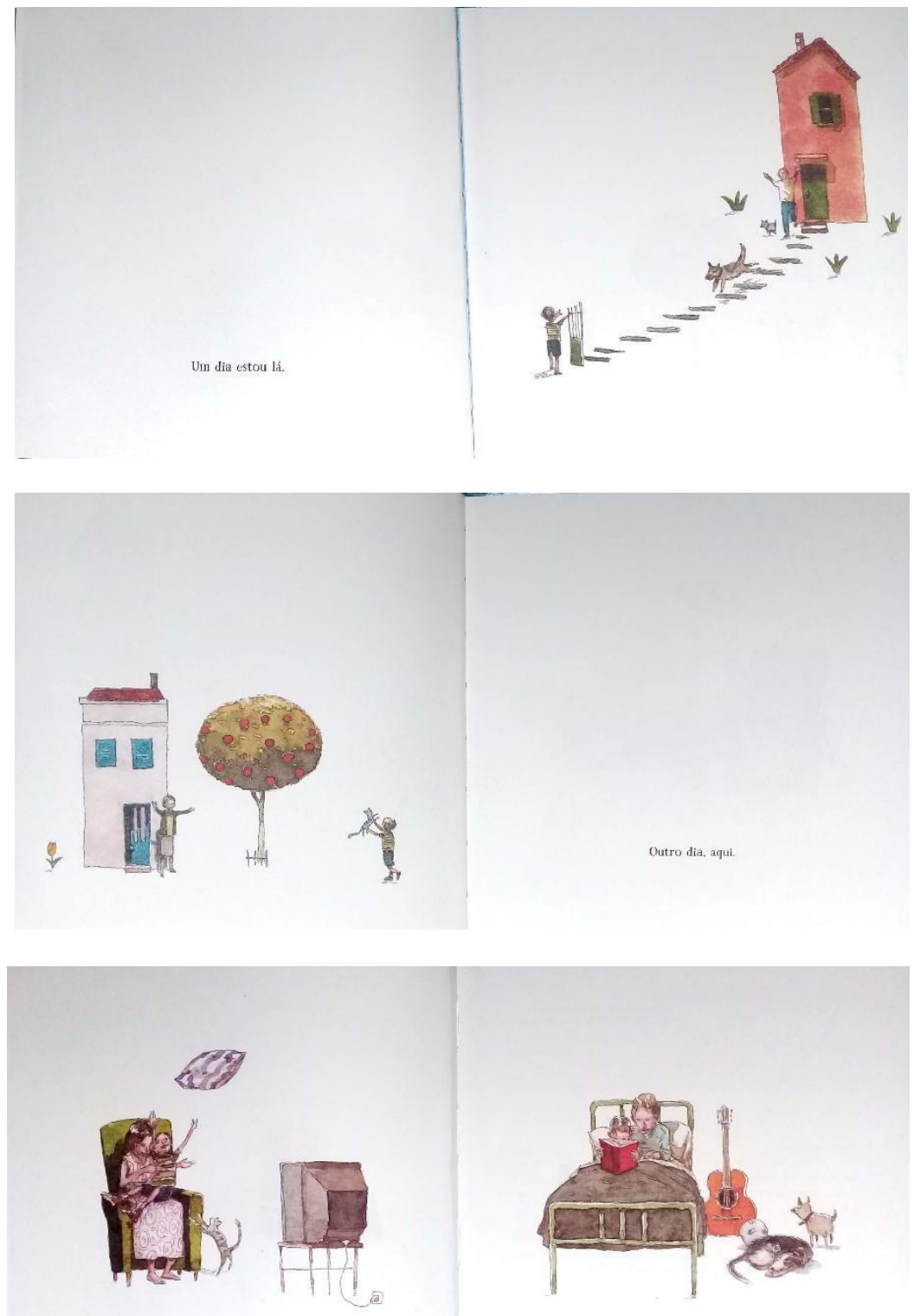

Mas estou sempre em casa.

Fonte: Moreyra e Moraes (2015)

A imagem é construída de forma sensível e afetiva, com um fundo branco em um espaço sem fundo que oferece um amplo campo à produção de sentidos, pois a concentração está no elemento humano presente na cena. Para constituição da leitura final, é preciso destacar alguns detalhes entre a composição do texto e da imagem: $O$ que os objetos dispostos nos ambientes da sala e do quarto podem sugerir? Qual a reação do menino em cada cena? Quais elementos podem sugerir a sensação de estar sempre em casa? $O$ que traz a familiaridade para o desfecho? Um bom indício é que as cores permanecem em tons suaves, estimulando o Revista Graphos, vol. 21, n 1, 2019 | UFPB/PPGL | ISSN 1516-1536 
acolhimento afetivo entre os personagens. Apenas alguns pontos mais escuros, de verde, roxo, vermelho e laranja, se destacam sem destoar do conjunto e garantem uma certa temperatura empática mais quente. Os cômodos dispostos na página não são os mesmos e criam a sensação para o leitor de mesma habitação: a mãe na sala e o pai no quarto. A casa agora é vista por dentro. O menino está acolhido e feliz em cada um desses ambientes, com o que cada um pode lhe dar de melhor. O menino tem o seu mundo reconstituído em duas casas que são uma só.

\section{Considerações finais}

O livro ilustrado pode ser definido por sua especificidade e materialização constituída por duas linguagens. A intricada relação de interdependência entre estas linguagens traz uma demanda mais complexa para o leitor. Para proceder a uma leitura adequada e vivenciar experiências estéticas significativas, o leitor precisa atentar para o rico diálogo entre o texto escrito e o visual. Nesse sentido, temos a necessidade, por um lado, de construir vários questionamentos diante dos recursos apresentados no livro ilustrado, e, por outro, de disseminar os aspectos do alfabetismo visual. A aprendizagem dessa capacidade leitora para as imagens pode ser iniciada nos livros ilustrados, apreendendo as possibilidades expressivas contidas nas formas, texturas, composições e perspectivas das obras infantis.

No livro Lá e aqui, é por meio das formas com traço mais aberto, dos tons suaves e linhas naturais que a afetividade transmite empatia. Esses e outros recursos constroem o difícil e doloroso percurso da separação dos pais. O texto curto mantém a dramaticidade poética e a tensão a cada virar de página. Ao longo do livro temos relações diferentes entre o texto e a imagem; ora essa relação é de correspondência, tudo o que é apresentado no texto corresponde ao que está na imagem, ora essa relação se torna mais pontual, quando, por exemplo os peixinhos vão morar nos olhos da mãe. O simbolismo do texto concentra de forma poética a tristeza que inunda os olhos da mãe, que é transferida para a imagem em cores e formas. $\mathrm{O}$ movimento para compreender esses sentidos só é possível com os questionamentos de natureza inferencial.

Dessa forma, ao centrar nossa leitura nas possibilidades que o exercício de inferência nos traz, devemos considerar os elementos gráficos relacionando-os aos dados do texto e às informações que podem ser percebidas como itens na construção dos sentidos. O resultado da leitura realizada mostra que os elementos gráficos dispostos no livro ilustrado constroem significados abertos à investigação do leitor, mas só podem ser relacionados na medida em que 
sejam considerados em conjunto e percebidos como fundamento da narrativa, e não apenas como referências ao texto fonte. A imagem não é uma unidade simples e direta, e guarda muitas especificidades, necessitando tanto da articulação coerente entre seus elementos, como com os elementos do texto escrito para suportar a finalidade de transmitir e comunicar eventos do enredo. No entanto, percebemos que, à medida que o livro ilustrado apresenta relações mais intricadas entre texto e imagem, a construção de sentido exige mais do leitor. O espaço conquistado pelo livro ilustrado é extenso em contexto escolar, mas ainda é necessária uma ampliação da formação dos leitores e dos mediadores.

\section{Referências}

CAMARGO, Luís. A criança e as artes plásticas. In: ZILBERMAN, Regina (org.). A produção cultural para a criança. Porto Alegre: Mercado Aberto. 1982.

. A ilustração do livro infantil. Belo Horizonte: Editora Lê, 1997.

COLOMER, Teresa. Andar entre livros: a leitura literária na escola. Tradução de Laura Sandroni. São Paulo: Global, 2007.

FARIA, Maria Alice. Como usar a literatura infantil na sala de aula. São Paulo: Contexto, 2004.

GIROTTO, Cinthia, SOUZA, Renata Junqueira de. Ler e compreender: estratégias de leitura. São Paulo: Mercado das Letras, 2011.

GÓES, Lucia Pimentel. Olhar de descoberta: proposta analítica de livros que concentram várias linguagens. Paulinas: São Paulo, 2003.

LAJOLO, Marisa, ZILBERMAN, Regina. Literatura infantil brasileira: uma nova outra história. São Paulo: PUCPress, 2017.

LAJOLO, Marisa, ZILBERMAN, Regina. Literatura infantil brasileira: história e histórias. São Paulo: Ática, 1991.

LINDEN, Sophie Van der. Para ler o livro ilustrado. Tradução de Dorothée de Bruchard. São Paulo: Cosac Naify, 2011.

MOREYRA, Carolyna, MORAES, Odilon. Lá e aqui. São Paulo: Zahar, 2015.

NIKOLAVEJA, Maria, SCOTT, Carole. Livro ilustrado: palavras e imagens. São Paulo: Cosac Naify, 2011.

PAIVA, Aparecida et al. Literatura na infância: imagens e palavras. UFMG, Centro de Alfabetização, Leitura e Escrita, 2008. Brasília Ministério da Educação, Secretaria de Educação Básica; Belo Horizonte. 
RAMOS, Flávia B., PANOZZO, Neiva S.P. Entre a ilustração e a palavra: buscando pontos de ancoragem. Espéculo. Revista de estudios literarios. Universidad Complutense de Madrid, 2004. Disponível em: 〈http://www.ucm.es/info/especulo/numero26/ima_infa.html〉. Acesso em 23 de novembro de 2018.

RAMOS, Graça. A imagem nos livros infantis - caminhos para ler o texto visual. São Paulo: Autêntica, 2011.

SALISBURY, Martin, STYLES, Morag. Livro infantil ilustrado: a arte da narrativa visual. São Paulo: Rosari, 2013.

SOLÉ, Isabel. Estratégias de leitura. 6. ed. Tradução de Cláudia Schilling. Porto Alegre: Artmed, 1998.

WERNECK, Regina Iolanda. O problema da ilustração no livro infantil. In: KHEDE, Sonia Salomão (org). Literatura Infantil: um gênero polêmico. Rio de Janeiro: Vozes, 1983.

Recebido em: 10/02/2019 Aceito para publicação em: 17/03/2019 